\title{
A Trajetória do Dr. Joaquim Manuel de Macedo no Segundo Reinado
}

\section{The Trajectory of Dr. Joaquim Manuel de Macedo in the Second Empire}

DOI: $10.46814 /$ lajdv3n3-034

Recebimento dos originais: 01/052021

Aceitação para publicação: 31/06/2021

\section{Rafael de Almeida Daltro Bosisio}

Doutorando pelo Programa de Pós-Graduação em História Social da Universidade Federal do Rio de Janeiro. Bolsista CAPES.

E-mail: rdaltro@ig.com.br

\section{RESUMO}

Joaquim Manuel de Macedo foi o primeiro escritor romântico brasileiro de grande repercussão. Apesar de ter sido um dos maiores literatos do Segundo Reinado, Macedo acabou esquecido no século XX, tendo, de toda a sua extensa e popular obra, apenas o romance A Moreninha sustentado a popularidade. No intuito de compreender como ocorreu essa perda de prestígio de Macedo, o trabalho aqui desenvolvido tem como objetivo central a trajetória de vida do romancista e, como específico, pensar a circulação do autor entre os mais diversos 'espaços de sociabilidade' da corte do Rio de Janeiro. Para isso, o trabalho está dividido em três partes: na primeira, é descrita a trajetória de Joaquim Manuel de Macedo utilizando alguns críticos que trabalharam sua obra, principalmente Antônio Cândido; na segunda, faz-se uma análise do escritor dentro do movimento literário romântico. E, por último, uma pequena conclusão, não esgotando o assunto e deixando-o em aberto para investigações futuras.

Palavras-Chave: Império; Literatura; Romantismo

\begin{abstract}
Joaquim Manuel de Macedo was the first Brazilian romantic writer of great repercussion. Despite being one of the best writers of the Second Reign, Macedo rested forgotten in the twentieth century and, among his extensive and popular work, only the romance A Moreninha held its popularity. To comprehend this loss of prestige, this paper focuses mainly the romanticist's trajectory of life and specifically his circulation through the various "spaces of sociability" in the court of Rio de Janeiro. Therefore, this work is divided in three parts: in the first, Macedo's trajectory is described by use of some critics that discussed his work, especially Antonio Candido; in the second part, an analysis of the writer along with the romantic literary movement is taken; and finally a short conclusion, which doesn't finish the subject, but leaves it open for further investigations.
\end{abstract}

Key-Words: Empire, Literature, Romanticism

\section{INTRODUÇÃO}

Joaquim Manuel de Macedo foi o primeiro escritor romântico brasileiro de grande repercussão. Apesar de ter sido um dos grandes literatos do Segundo Reinado, Macedo acabou esquecido no século XX, tendo, de toda a sua extensa e popular obra, apenas o romance A Moreninha sustentado a popularidade. 
A repercussão deste primeiro sucesso foi tão grande que perdura até hoje, sendo, alguns anos depois de sua publicação, apontada pelo romancista José de Alencar: "naqueles bons tempos da mocidade, deleitava-o a literatura, e era entusiasta do Dr. Joaquim Manoel de Macedo, que pouco havia publicara o seu primeiro e gentil romance - A Moreninha",

No intuito de compreender como ocorreu essa perda de prestígio de Macedo, o trabalho aqui desenvolvido tem como objeto central a trajetória de vida do romancista e, como específico, pensar o mesmo como um autor que circulou entre os mais diversos 'espaços de sociabilidade' da corte do Rio de Janeiro. Para isso, o trabalho está dividido em três partes. A primeira, faço uma pequena biografia de Joaquim Manuel de Macedo (onde está descrita sua trajetória de vida, englobando aspectos pessoais e profissionais) utilizando alguns críticos que trabalharam sobre ele, principalmente Antônio Cândido; na segunda, faço uma análise do escritor dentro do movimento literário romântico. E, por último, uma pequena conclusão.

Duas expressões que permeiam o trabalho merecem esclarecimentos. A primeira sociabilidade - deve ser entendida, segundo Georg Simmel, como uma forma autônoma de sociação, uma forma de vida societária. Logo, "sociedade propriamente dita é o estar com um outro, para um outro, contra um outro que, através do veículo dos impulsos ou dos propósitos, forma e desenvolve os conteúdos e os interesses materiais ou individuais"ii . Esse processo resulta em formas que ganham vida própria e são liberadas dos conteúdos, passando a existirem por si mesmas.

A segunda expressão é espaço público, e é utilizada de acordo com as três possibilidades dadas por Marco Morel, isto é:

Cena ou esfera pública, onde interagem diferentes atores, e que não se confunde com o Estado; a esfera literária e cultural, que não é isolada do restante da sociedade e resulta da expressão letrada ou oral de agentes históricos diversificados; e os espaços físicos ou locais onde se configuram estas cenas e esferas ${ }^{\mathrm{iii}}$.

Sem a presunçosa intenção de esgotar o tema, o trabalho tem a intenção de contribuir para recuperação da figura de Joaquim Manuel de Macedo, como sendo um intelectual que enxergou na literatura uma via de execução do projeto de construção da nação brasileira.

\section{O SR. DR. JOAQUIM MANUEL DE MACEDO}

Joaquim Manuel de Macedo foi o primeiro escritor romântico de grande repercussão no Brasil. Entre 1844 e 1882, Macedo exerceu inúmeras atividades e atribuições: escreveu romances; participou ativamente da vida intelectual e política do Segundo Reinado; foi articulista em diversos jornais; membro do Instituto Histórico e Geográfico do Brasil; político. Enfim, um verdadeiro "homem de 
letras". Essa versatilidade possibilitou ao escritor uma capacidade de circulação entre diversos espaços públicos - e suas diferentes formas e práticas de sociabilidade - existentes na corte.

Nascido em 24 de junho de 1820, na Vila de São João de Itaboraí, Macedo passou a infância nessa vila, vindo para o Rio de Janeiro, nos anos 30, para cursar os preparatórios para o ingresso na Faculdade de Medicina. No decorrer de seus estudos na corte, Macedo passa a demonstrar grande interesse pelas letras, sendo atraído principalmente pelo jornalismo e pelas manifestações culturais associadas ao Romantismo - gênero literário recém-chegado ao Brasil. Com uma nova maneira de ver o mundo e a natureza, o Romantismo e sua ânsia por liberdade chegam ao Brasil recém-independente no mesmo momento que se desejava a construção de uma identidade nacional, desta maneira uma de suas características é logo posta em evidência - a valorização da nação e de suas tradições. Neste contexto, os escritores ambicionam a criação de uma literatura autenticamente brasileira e este esforço, segundo Antônio Cândido, era visto como "um ato de brasilidade"iv.

No início de 1844, Macedo publicou seu primeiro livro - A Moreninha -, que logo se tornou sucesso de público e crítica, e seria o grande marco de sua trajetória de escritor. No mesmo ano, em dezembro, ele defendeu, com êxito, a sua tese de conclusão de curso, chamada Considerações sobre a Nostalgia. Durante algum tempo, Macedo atuou como médico em sua cidade natal, clinicando principalmente para as camadas mais baixas da população, que passou a chamá-lo carinhosamente de "Doutor Macedinho". Sua tese trata de temas de psicologia e psiquiatria, bastante comuns durante os anos de 1840, se inserindo no momento de institucionalização acadêmica destas duas ciências no

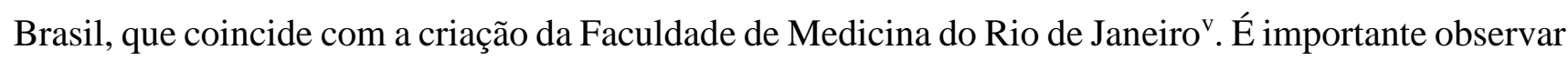
que a nostalgia é um tema bastante recorrente na literatura romântica e traz em seu bojo a construção de uma ideia de pátria, pois sua caracterização é ligada à questão do deslocamento e do desenraizamento.

Dentre suas múltiplas atividades, Macedo trabalhou no magistério, como membro do Conselho Diretor de Instrução Pública na Corte e lente de História do Brasil, e, a partir de 1858, de corografia do Imperial Colégio Pedro II. Na imprensa, escreveu para diversos jornais e revistas, como o Jornal do Commercio, Minerva Brasiliense, Ostensor Brasileiro, A Reforma e Semana Ilustrada, além de, em 1849, ter fundado, com Gonçalves Dias, Gonçalves Magalhães, Fernandes Pinheiro e Manoel Araújo Porto-Alegre, a Revista Guanabara, em que publicou seu poema-romance A Nebulosa. Participou, também, da vida política fluminense escrevendo no jornal $A$ Nação, do Partido Liberal, pelo qual foi eleito em diferentes oportunidades - para a Assembleia Provincial do Rio de Janeiro em 1854 e para a Assembleia Geral Legislativa, nos anos de 1864/1866, 1867/1868 e 1878/1881.

Em 1845, entrou para o Instituto Histórico e Geográfico Brasileiro (IHGB) como membro efetivo, participando do momento fundador da historiografia brasileira ${ }^{\text {vi }}$. Eleito por unanimidade, foi 
um dos poucos que ingressaram no instituo com menos de vinte e cinco anos e, em 1848 , foi eleito $2^{\circ}$ Secretário. Três anos depois, foi eleito membro da Comissão de Trabalhos Históricos e $1^{\circ}$ Secretário, responsável pelos relatórios anuais nas sessões magnas. Em 1857, foi eleito orador efetivo, cargo que ocupou por quase vinte e cinco anos, tendo, em 1876, ocupado interinamente a presidência do instituto. Macedo produziu pouco como historiador; além relatórios como $1^{\circ}$ secretário, dos discursos como orador e pareceres presentes nas revistas do instituto, possui apenas duas obras históricas - Dúvidas sobre alguns pontos da História do Brasil e Ano Biográfico Brasileiro ${ }^{\text {vii }}$, esta destinada à Exposição Universal da Filadélfia.

No entanto, também podem ser consideradas como obras históricas seus compêndios de história do Brasil ${ }^{\text {viii }}$. Assunto muitas vezes debatido nas sessões e nas páginas da revista do IHGB, a questão da criação de compêndios de história do Brasil apropriados, voltados para a "instrução do povo" (palavras do próprio Macedo), foi constante preocupação de Macedo. Inspirados na História Geral do Brasil, de Francisco Adolfo de Varnhagen, os compêndios de Macedo também estão preocupados, de maneira mais didática, com a construção da nação, apontando as direções em que a história do Brasil deveria ser entendida.

No momento em que Macedo escreve seus livros, a história está se institucionalizando como uma disciplina nova, que, além da função de "mestra da vida", passa a ter um caráter mais "fílosófico". Ela se torna "um terreno privilegiado da demonstração do sentido da existência social"ix . Com a busca do progresso e da civilização nos povos e nações, a narrativa histórica passa a se apresentar como a biografia da nação.

Segundo Selma Mattos, "mais do que os contrastes entre os sucessos nas duas atividades [de historiador e professor], o que singulariza o Macedo autor das Lições é a unidade que acabou por estabelecer entre as mesmas" ". Em suma, Macedo conseguiu de modo significativo articular as duas atividades, proporcionando o conhecimento da história "verdadeira" pela via do ensino público.

O romancista também atuou no espaço público do teatro, através da dramaturgia e como membro do Conselho do Conservatório Dramático do Rio de Janeiro, onde era censor. Desse interesse resultaram muitas peças entre 1849 e 1880 e incentivos às companhias e sociedades teatrais, levando Sílvio Romero ${ }^{\mathrm{xi}}$ constatar que o Macedo escritor de peças superou qualitativamente o escritor de romances.

Macedo foi ainda membro da Sociedade Auxiliadora da Indústria Nacional e Comendador da Ordem da Rosa e de Cristo. Na Academia Brasileira de Letras é o patrono da cadeira número 20.

Doutor Macedinho foi um escritor muito popular, e publicou seus romances durante anos no Jornal do Commercio, em forma de folhetim ${ }^{\mathrm{xii}}$. Essa popularidade se deu devido ao tom ameno e moralizante, às intrigas amorosas e personagens sentimentais, bem ao gosto dos leitores da época. Com 
estas características, Macedo adentrou nos lares em que se cultivava a leitura, tornando-se um escritor querido do público, chegando a ser professor das princesas D. Isabel e D. Leopoldina, e estimado pela família imperial.

Todo esse afeto, que o público dedicava a Macedo, ele retribuiu com crônicas sobre a cidade do Rio de Janeiro. Nessas ele descreveu os costumes urbanos e o ambiente da cidade do Rio de Janeiro no apogeu do Império. Como aponta Fátima Rocha, "Macedo transita das crônicas do tempo para a tradição oral e desta, outra vez, para a fiel narração dos fatos"xiii, e, nesse sentido, a autora nomeia Macedo como um cronista-em-trânsito, responsável pelo mapeamento histórico-geográfico da Corte.

Essa capacidade descritiva faz Antônio Cândido lembrar que a Macedo:

Cabe a glória de haver lançado a ficção brasileira na senda dos estudos de costumes urbanos, e o mérito de haver procurado refletir fielmente os da sua cidade. $\mathrm{O}$ valor documentário permanece grande, por isso mesmo, na obra que deixou. Os saraus, as visitas, as partidas, as conversas; os domingos na chácara, os passeios de barca; as modas, as alusões à política; a técnica do namoro, de que procura elaborar verdadeira fenomenologia; a vida comercial e o seu reflexo nas relações domésticas e amorosas - eis uma série de temas essenciais para compreender a época, e que encontramos bem lançados em sua obra, de que constituem talvez o principal atrativo para o leitor de hoje $\mathrm{e}^{\mathrm{xiv}}$.

Na vida amorosa, entre os anos de 1835 e 1850, Macedo conheceu e casou-se com Maria Catarina Sodré, que era prima-irmã do poeta ultra-romântico Álvares de Azevedo. Semelhante aos seus heróis e suas heroínas, Macedo enfrentou diversos obstáculos para conseguir sua amada, vencendo a oposição do pai dela, e concretizando o casório após dez anos de namoro. Seu casamento não lhe proporcionou filhos. Segundo conta o biógrafo Ernesto Sena, ao conversar com Catarina quando ela já estava viúva, ela lhe revelou: “Oh! Ele me queria muito, sinceramente. Raras vezes saía à rua sem ser minha companhia. Fui feliz, muito feliz" ${ }^{\mathrm{xv}}$. Essa felicidade no casamento transparece também em seus escritos, com o tom moralizante, com o marido fiel, a esposa dedicada e o final feliz.

Em 11 de abril de 1882, depois de sofrer durante dois anos de uma doença possivelmente de origem mental, Joaquim Manuel de Macedo faleceu em Itaboraí.

\section{UM HOMEM EM SEU TEMPO}

Doutor Macedinho foi um escritor popular. Essa popularidade se deve ao tom ameno e moralizante, com intrigas amorosas e personagens sentimentais, voltados sempre para o final-feliz com o casamento entre os personagens, bem ao gosto dos leitores da época. Com estas características Macedo penetrou nos lares das que eram consideradas boas famílias da sociedade fluminense, onde se cultivava a leitura, tornando-se um escritor querido do público. Nesses lares eram, em sua maioria, as senhoras, as donzelas, enfim, as mulheres, que liam esses romances. Logo, as obras de Macedo 
circulavam no próprio espaço que elas descreviam, visto que o próprio escritor ressaltava o tratamento do leitor, referindo-se sempre a ele como sendo uma leitora, uma senhora.

Os anos de 1830 foram o ponto de partida de uma nova fase da vida intelectual brasileira. Houve uma dinamização e progresso de todos os gêneros de produção literária, sendo o ano de 1836 um marco, pois, com a publicação de Suspiros Poéticos e Saudades, de Gonçalves Magalhães, e, principalmente, da revista Niterói, Revista Brasiliense de Ciências, Letras e Artes (na França), do grupo de Gonçalves Magalhães, Araújo Porto-Alegre e Torres-Homem, os ideais do movimento romântico foram muito divulgados no Brasil.

Logo, em uma simbiose dos campos intelectual e político, há uma preocupação da elite dirigente com a construção da identidade nacional, de uma história nacional. E nesse quadro, o Romantismo, com suas características renovadoras derivadas de iluminismo oitocentista, inicia um processo de consolidação da autonomia nacional, tanto no que diz respeito à literatura, quanto nos outros campos das artes, abraçando a ideia de um projeto de construção de nação. Assim, o movimento romântico encontra um campo fértil para o seu crescimento, fazendo surgir no Brasil o romance como gênero, até então desconhecido pelo público brasileiro. As camadas médias urbanas, em crescimento, encontram no Romantismo e no romance-romântico o veículo de expressão de um estado de espírito repleto de sentimentos profundos, consumindo esses romances, a poesia e o teatro. A imprensa tem um papel fundamental de divulgação do movimento, pois a maioria dos romances é publicada nos jornais, sob a forma de folhetim, para o consumo de seu público.

Nesse contexto, Joaquim Manuel de Macedo surge como um autor de transição, que ajuda a consolidar o Romantismo no Brasil, com o seu "romance de costumes, de um realismo misturado ao destempero melodramático, ou atenuado pelo bom humor mediano”, como diz Antônio Cândido ${ }^{\text {xvi }}$. Ou de uma maneira mais didática, é possível referir Macedo como pertencente à primeira geração de românticos ${ }^{\mathrm{xvii}}$, pois é certo que seu romance de estreia, A Moreninha, além de ter obtido sucesso de público, consolidou o gênero romance no Brasil, dando forma e consistência a ele. A importância que Macedo teve no desenvolvimento desse gênero pode ser sentida pela seguinte observação de Antônio Cândido:

O pequeno valor literário da sua obra é principalmente social, pelo fato de ele se ter esforçado em transpor a um gênero novo entre nós os tipos, as cenas, a vida de uma sociedade em fase de estabilização, lançando mão de estilo, construção, recursos narrativos os mais próximos possíveis da maneira de ser e falar das pessoas que o iriam ler ${ }^{\text {xviii }}$.

Antônio Cândido também aponta para um aspecto importante do papel social de Macedo, quando assinala que: 
Na obra de Macedo, aparece pela primeira vez no Brasil a figura virtualmente profissional do escritor, o homem que mesmo não vivendo da sua obra (que seria impossível no acanhado meio do Rio de Janeiro daquele tempo), se apresenta e é avaliado como produtor regular de textos que formam um conjunto, mediante o qual será aplaudido ou rejeitado. O seu papel social, sob este aspecto, foi decisivo ${ }^{\text {xix }}$.

O impacto de sua obra foi sentido tanto na sociedade que ele representava em seus romances, quanto nos escritores românticos que vieram após sua primeira publicação. Assim, Macedo foi um escritor que, apesar de ter sofrido duras críticas durante o século XX, chegou até o XXI, para o grande público, como o autor de um romance - A Moreninha. Já no campo de pesquisa, seus romances chegaram como belos exemplares de romances de costumes, nos quais aparece descrito o universo social da corte fluminense.

O teatro de Macedo é tipicamente romântico, já que recorreu à apresentação didática de uma ética pública e serviu como instrumento de comunicação que ajudou a preparar o público para aceitar e apreciar o romance. Suas peças alternavam-se entre dramas e comédias e possuem um forte tom moralizante, pois, para Macedo, deveria se atribuir um fim educativo ao teatro.

No teatro de Macedo há a permanência de determinadas práticas do teatro do Primeiro Reinado. Levando em consideração Marco Morel, quando aponta que o teatro brasileiro do século XIX (principalmente o da primeira metade) é um espaço público híbrido ${ }^{\mathrm{xx}}$, onde coexistem práticas do Antigo Regime com práticas modernas e suas rupturas e continuidades, algumas peças de Macedo possuem forte caráter panfletário à favor do Partido Liberal, do qual Macedo era membro.

Peças como Amor à Pátria e Torre em Concurso, contavam com a reação do público para verificar a adesão pública ou não a determinado gabinete (também a determinadas posições do próprio monarca), funcionando como uma espécie de opinião pública. Assim, o teatro não era utilizado apenas como um espaço de celebração e entretenimento, mas também como um espaço para de conflito político, social e, até mesmo, racial, confirmando a permanência de traços do ambiente teatral do Primeiro Reinado ${ }^{\mathrm{xxi}}$.

Macedo ambienta sua obra, em grande parte, no espaço doméstico: retrata as formas e práticas de sociabilidade dos salões fluminenses (que tinham em sua composição uma camada social rica e afrancesada), apresenta personagens ligados à corte e descreve minuciosamente todo o luxo e ostentação que permeava essa sociedade. Talvez nesse ponto resida o valor e a importância de Macedo, pois, através de um retrato fiel da ordem social do Segundo Reinado, colaborava para sua conservação e, até mesmo, expansão.

A palavra romance, utilizada no trabalho, diz respeito ao termo romance-romântico, que possui uma função específica naquela sociedade, diferente da que ele ocupa hoje. O romance-romântico era uma forma de entretenimento familiar, ocupando quase a mesma função que a telenovela tem 
atualmente. Assim, o romance adentrava o espaço da casa e, consequentemente, o espaço feminino, pois a casa era o espaço da mulher ${ }^{x x i i}$. Os romancistas conseguiam, além de atender a demanda desse público específico ${ }^{\text {xxiii }}$, retratar esse espaço fielmente, com suas práticas e formas sociais, daí a existência de uma forte relação entre os romancistas e o público feminino.

O romance-romântico também possuía um caráter de moralidade e civilidade, que estavam dentro do projeto civilizatório das elites políticas do Segundo Reinado. Esse caráter moralizante é apontado por José Veríssimo, no trecho em que se refere aos romances de Macedo: "São romances morais, de família; leitura para senhoras e senhoritas de uma sociedade que deles próprios se verifica inocente, pelo menos sem malícia, e que, salvo os retoques romanescos, essas novelas parecem que retratam fielmente"xxiv.

Já o romance como possuidor de um caráter de civilidade, pressupõe que este estava entrelaçado a um projeto de construção da nação, logo, o romance seria um instrumento que estaria presente tanto na construção da nação, quanto na da civilidade dentro da sociedade imperial. É nesse sentido que Antônio Cândido observa:

E como além de recurso estético foi um projeto nacionalista, fez do romance verdadeira forma de pesquisa e descoberta do país. A nossa elite cultural intelectual encontrou nisto um elemento dinamizador de primeira ordem, que contribuiu para fixar uma consciência mais viva da literatura como estilização de determinadas condições sociais. O ideal romântico-nacionalista de criar uma expressão nova de um país novo encontra no romance a linguagem mais eficiente $^{\mathrm{xxv}}$.

\section{CONCLUSÃO}

Joaquim Manuel de Macedo foi um dos escritores mais lidos de seu tempo, entretanto chegou ao século XX e XXI como autor de um único romance - A Moreninha. Autor fecundo, Macedo teve diversas atividades, destacando-se nas de escritor e professor.

Sua obra está no bojo tanto da construção como da divulgação do projeto civilizatório das elites políticas do Segundo Reinado. Estas acreditavam que deveriam construir uma nação baseada no ideal civilizatório da corte francesa de Napoleão III, ou, nas palavras do historiador Marques dos Santos, uma Europa possível ${ }^{\mathrm{xxvi}}$. Assim, uma das questões deste momento era como implementar este projeto que tinha como principal objetivo inserir a nação brasileira no rol dos países civilizados.

Ademais, seus escritos possuem um caráter didático que visava formar uma nova mentalidade ética para a burguesia emergente do Segundo Reinado - já que esta era desprovida de uma bagagem moral adequada - e destacava o seu papel na tarefa de construção da nacionalidade, ou seja, na tarefa de forjar a nação. Assim, Fátima Rocha diz que "os folhetins de Macedo dão exemplo da passagem, nas figurações do país e da Corte, de um paisagismo naturalístico para um paisagismo histórico"xxvii. 
Conclui-se que a obra de Macedo é marcada pelos diversos espaços sociais que eram frequentados pelo próprio escritor. Em primeiro lugar, nos romances e crônicas, existe uma descrição cuidadosa do ambiente das camadas mais abastadas da sociedade fluminense e de suas diferentes práticas e formas de sociabilidade. Em segundo lugar, Macedo consegue atender as normas de escrita exigidas de cada espaço que frequentava, escrevendo de acordo com a exigência de cada tipo específico de público.

Assim, Macedo conseguiu circular entre diferentes espaços sociais, respeitando e seguindo as mais variadas formas de sociabilidade que cada espaço exigia. Vivia o seu tempo intensamente com ativa participação na vida política e intelectual, buscando sempre o ideal romântico de construir uma nação que fosse uma civilização nos trópicos. 


\section{REFERENCIAS}

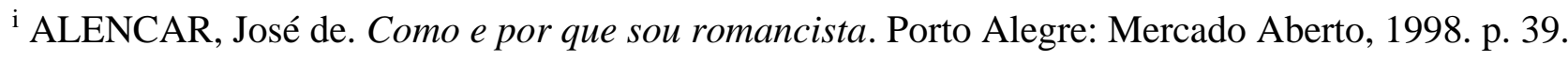

ii SIMMEL, Georg. "Sociabilidade - um exemplo de sociologia pura ou formal”. In: MORAIS FILHO, Evaristo de (org.) Georg Simmel: sociologia. São Paulo: Ática, 1983. p. 168.

iii MOREL, Marco. As transformações dos espaços públicos. Imprensa, atores políticos e sociabilidades na cidade imperial (1820-1840). São Paulo: Hucitec, 2005. p. 18.

iv CÂNDIDO, Antônio. Literatura e Sociedade. São Paulo: Publifolha, 2000. (Grandes nomes do pensamento brasileiro). p. 73.

${ }^{\vee}$ LOPES, Myriam Bahia; POLITO, Ronald. Posfácio de Considerações sobre a nostalgia, de Joaquim Manuel de Macedo. São Paulo: Unicamp, 2004. p. 115.

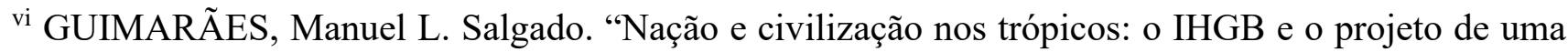
história nacional". Estudos históricos, Rio de Janeiro, v.1, n. 1, p. 5-27, 1988.

vii Esta obra contém biografias de brasileiros ilustres, que Macedo, como orador do IHGB, já tinha escrito. Além dessas duas obras, Macedo deixou incompleta Efeméride histórica do Brasil.

viii São os compêndios: Lições de história do Brasil para uso dos alunos do Imperial Colégio Pedro II ( $4^{\circ}$ ano - 1861); Lições de história do Brasil para uso dos alunos do Imperial Colégio Pedro II ( $7^{\circ}$ ano - 1863); Lições de história do Brasil para uso das escolas de instrução primária (1865).

ix FURET, François. “O nascimento da História”. In: A oficina da história. Lisboa: Gradiva, 1990. (Construir o Passado 8). p. 121.123.

${ }^{x}$ MATTOS, Selma Rinaldi de. O Brasil em lições: a história como disciplina escolar em Joaquim Manuel de Macedo. Rio de Janeiro: Access, 2000. (Coleção Aprendizado do Brasil 1). p. 61.

${ }^{x i}$ ROMERO, Sílvio. História da Literatura Brasileira. $3^{\text {a }}$ ed. Rio de Janeiro: José Olímpio, 1943.

xii $\mathrm{O}$ folhetim era um novo "fazer" literário, uma via de comunicação fácil, ágil, informativo e crítico, no entanto não podia perder o tom de fantasia e sonho, assim não seria enfadonho para o leitor. Era escrito e publicado diariamente nos jornais (o escritor escrevia exaustivamente). Funcionando como as novelas atuais, causando certa expectativa no público sobre o que ocorreria no próximo capítulo. Ver: MEYER, Marlyse. Folhetim: uma história. São Paulo, Companhia das Letras, 2007.

xiii ROCHA, Fátima Cristina Dias. "Três passeios pela cidade carioca: figurações do Rio de Janeiro em Joaquim Manuel de Macedo, Lima Barreto e Rubem Fonseca”. In: OLIVEIRA, Ana Lúcia M. de. Linhas de fuga: trânsitos ficcionais. Rio de Janeiro: 7letras, 2004. p. 73.

${ }^{\text {xiv }}$ CÂNDIDO, Antônio. Formação da literatura brasileira: momentos decisivos. 8 ed. Belo Horizonte: Itatiaia Limitada, 1997. v. 2. p. 129.

${ }^{\mathrm{xv}}$ SENA, Ernesto. História e histórias. Paris, Buenos Aires: Casa Editorial Hispano-Americana, [19-]. p. 65-82. 
xvi CÂNDIDO, Antônio. Iniciação à literatura brasileira: resumo para principiantes. São Paulo: Humanitas/FFLCH/USP, 1999. p. 45.

xvii JOZEF, Bella. Joaquim Manuel de Macedo. Rio de Janeiro: Agir, 1971. (Nossos Clássicos). p. 7.

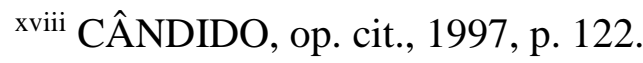

${ }^{\text {xix }}$ CÂNDIDO, op. cit., 1999, p. 45.

xx "O teatro começa assim a tornar-se não apenas um lugar de aclamação, mas de diálogo, conflito e consenso. Ou seja, um espaço híbrido, em vários sentidos: entre a rua e os recintos fechados, entre as noções de soberania monárquica e soberania popular, entre o oficial e o contestatório". MOREL, op.cit., p. 235.

xxi “A falta de lugares determinados para reuniões abertas na cidade imperial do Rio de Janeiro, ao longo do processo de Independência e consolidação da Nação, acabou transformando a sala do Teatro num espaço de manifestação política. Ou seja, num lugar de sociabilidade criador de mais um entre os diferentes níveis de espaços públicos [...] a sala de espetáculos foi tornando-se um canal da expressão de diferentes vontades coletivas [...] o público tornava-se ator político, sujeito histórico". MOREL, op. cit., p. 233.

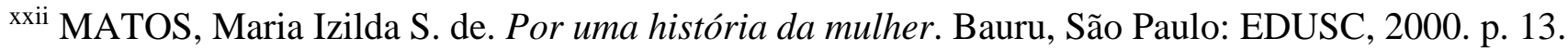

xxiii O público feminino (assim como o público romântico) ansiava por expressar um estado de espírito que estava impregnado de sentimentos que se encontravam sufocados pelas restrições sociais impostas.

xxiv VERÍSSIMO, José. História da literatura brasileira. 4ª ed. Brasília: Universidade de Brasília, 1981. p. 237-241.

${ }^{x x v}$ CÂNDIDO, op. cit., 1997, p. 99-100.

${ }^{x x v i}$ SANTOS, Afonso Carlos Marques dos. A invenção do Brasil: ensaios de história e cultura. Rio de Janeiro: Editora UFRJ, 2007.

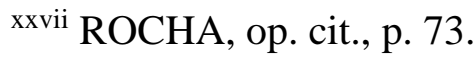

